\title{
The burden of hypoxic-ischaemic encephalopathy in Malaysian neonatal intensive care units
}

\author{
Nem-Yun $\underline{B O O}^{1}$, MBBS, FRCPCH, Irene Guat-Sim $\underline{C h e a h}^{2}$, MBBS, FRCPCH
}

\begin{abstract}
INTRODUCTION This study aimed to determine the incidence of hypoxic-ischaemic encephalopathy (HIE) and predictors of HIE mortality in Malaysian neonatal intensive care units (NICUs).

METHODS This was a retrospective study of data from 37 NICUs in the Malaysian National Neonatal Registry in 2012. All newborns with gestational age $\geq 36$ weeks, without major congenital malformations and fulfilling the criteria of HIE were included.

RESULTS There were 285,454 live births in these hospitals. HIE was reported in 919 newborns and 768 of them were inborn, with a HIE incidence of 2.59 per 1,000 live births/hospital (95\% confidence interval [CI] 2.03, 3.14). A total of $144(15.7 \%)$ affected newborns died. Logistic regression analysis showed that the significant predictors of death were: chest compression at birth (adjusted odds ratio [OR] 2.27, 95\% Cl 1.27, 4.05; $\mathrm{p}=0.003$ ), being outborn (adjusted OR 2.65, 95\% Cl 1.36, 5.13; $p=0.004$ ), meconium aspiration syndrome (MAS) (adjusted OR 2.16, 95\% Cl 1.05, 4.47; $p=0.038$ ), persistent pulmonary hypertension of the newborn (PPHN) (adjusted OR 4.39, 95\% Cl 1.85, 10.43; $p=0.001$ ), sepsis (adjusted OR 4.46, 95\% Cl 1.38, 14.40; $p=0.013$ ), pneumothorax (adjusted OR 4.77, 95\% Cl 1.76, 12.95; $p=0.002$ ) and severe HIE (adjusted OR 42.41, 95\% Cl 18.55, 96.96; $p<0.0001$ ).

CONCLUSION The incidence of HIE in Malaysian NICUs was similar to that reported in developed countries. Affected newborns with severe grade of HIE, chest compression at birth, MAS, PPHN, sepsis or pneumothorax, and those who were outborn were more likely to die before discharge.
\end{abstract}

Keywords: hypoxic-ischaemic encephalopathy, predictors of early mortality, term newborns

\section{INTRODUCTION}

Hypoxic-ischaemic encephalopathy (HIE) is a serious condition that affects newborns. The incidence of HIE in developed countries was reported to range from 0.97 to 2.5 per 1,000 live births in the 1990s. ${ }^{(1-4)}$ Randomised controlled studies showed that early cooling therapy improved neurodevelopmental outcomes of newborns with HIE. ${ }^{(5)}$ To the best of our knowledge, the incidence, clinical characteristics and predictors of early outcome of HIE patients in Malaysia have not previously been reported. To address this gap in knowledge and assist Malaysian neonatologists in planning strategies to improve outcomes for this group of newborns, the Malaysian National Neonatal Registry (MNNR), which had a membership of 37 member neonatal intensive care units (NICUs) in 2012, included in its database all newborns diagnosed with HIE and admitted to their NICUs. We herein present the incidence, clinical characteristics and predictors of early outcome of newborns diagnosed to have HIE.

\section{METHODS}

This was a retrospective study using data collected prospectively from the MNNR of newborns delivered in the year 2012. We included all newborns who had a gestational age $\geq 36$ completed weeks, were diagnosed with HIE and were admitted to NICUs in the member hospitals. Preterm newborns with gestational age $<36$ completed weeks, and term newborns with major congenital malformations or inborn errors of metabolism were excluded.

HIE was diagnosed if all of the following three criteria were met: (a) any three features of encephalopathy within 72 hours of birth, such as abnormal level of consciousness (e.g. hyperalert state, lethargy, stupor or coma), abnormal muscle tone, abnormal deep tendon reflexes, seizure, abnormal Moro reflex, abnormal sucking reflex, abnormal respiratory pattern, and oculomotor or pupillary abnormalities; (b) three or more findings of acute perinatal events, such as arterial cord $\mathrm{pH}<7.00$, Apgar score $<5$ at five minutes of life, evidence of multi-organ system dysfunction within 72 hours of birth, evidence of fetal distress on antepartum monitoring, abnormal electroencephalogram, and abnormal imaging of the brain showing ischaemia or oedema within seven days of birth; and (c) the absence of any underlying congenital cerebral infections/abnormalities or inborn errors of metabolism that could account for the encephalopathy. ${ }^{(6)}$ The severity of HIE was graded as: mild when the newborn was alert or hyperalert with either normal or exaggerated response to arousal; moderate when the newborn was lethargic with diminished response to arousal manoeuvres; and severe when the newborn was in a deep stupor or coma at birth and not arousable in response to appropriate manoeuvres.

Newborns were categorised as appropriate for gestational age, small for gestational age and large for gestational age when their birth weights were in the 10th-90th percentile, $<10$ th percentile

${ }^{1}$ Department of Population Medicine, Faculty of Medicine and Health Sciences, Universiti Tunku Abdul Rahman, Selangor, ${ }^{2}$ Department of Paediatrics, Paediatric Institute, Hospital Kuala Lumpur, Kuala Lumpur, Malaysia

Correspondence: Dr Nem-Yun Boo, Senior Professor, Department of Population Medicine, Faculty of Medicine and Health Sciences, Universiti Tunku Abdul Rahman, Jalan Sungai Long, Bandar Sungai Long, 43000 Kajang, Selangor, Malaysia. boony@utar.edu.my 


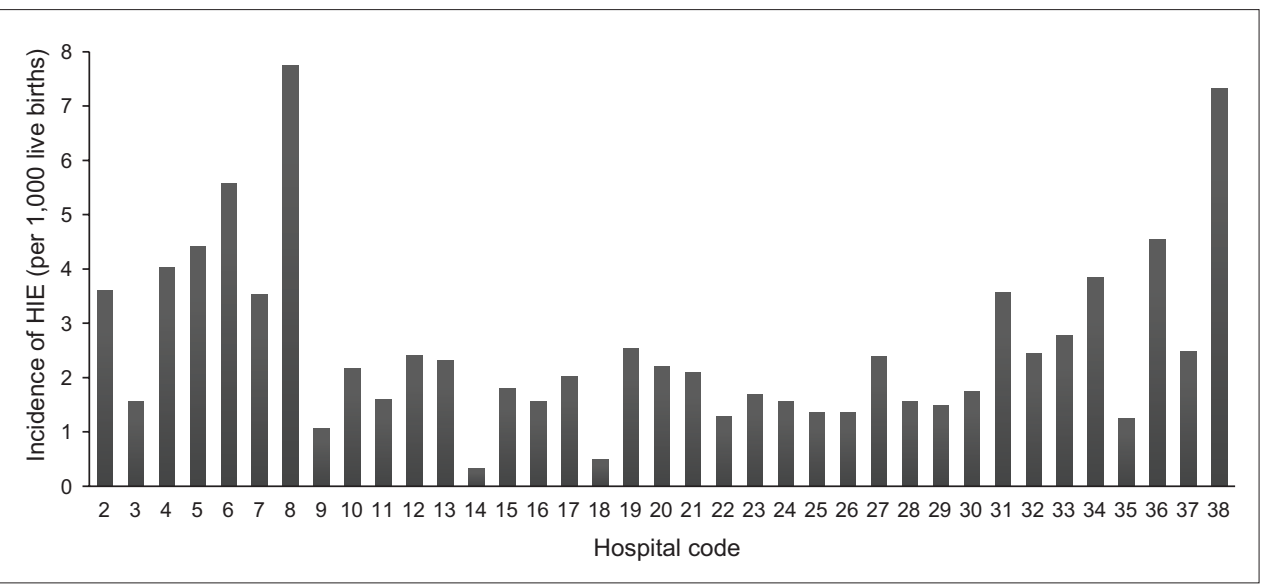

Fig. 1 Graph shows the incidence of hypoxic-ischaemic encephalopathy (HIE) in 37 Malaysian hospitals in 2012.

and > 90th percentile for their gestational age, respectively. ${ }^{(7)}$ Meconium aspiration syndrome (MAS) was diagnosed when the following five criteria were met: (a) meconium-stained amniotic fluid at birth; (b) onset of respiratory distress within one hour of birth; (c) partial pressure of oxygen in arterial blood $\left(\mathrm{PaO}_{2}\right)<50 \mathrm{mmHg}$, central cyanosis on room air or requiring supplemental oxygen to maintain $\mathrm{PaO}_{2}>50 \mathrm{mmHg}$; (d) an abnormal chest radiograph showing either coarse irregular or nodular pulmonary densities, areas of diminished aeration or consolidation alternating with areas of hyperinflation, or generalised hyperinflation; and (e) absence of culture-proven, early-onset bacterial sepsis or pneumonia. Pneumothorax was diagnosed based on radiological evidence. Sepsis was diagnosed given the presence of clinical signs and positive culture in the blood or cerebral spinal fluid.

The live birth census from each member hospital, organised according to mode of delivery, gestation and birth weight categories, was submitted to the MNNR at the end of each calendar month. At the end of the study, an online survey was conducted to identify the hospitals that had facilities for cooling therapy and cerebral function monitoring (CFM) during the study period and those that did not. The number of newborns with HIE and their outcomes in these two groups of hospitals were compared.

The incidence of HIE at each hospital was calculated by dividing the number of inborn newborns with HIE by the total number of live births at the respective hospital in 2012 and multiplying by 1,000 . Descriptive statistics were reported as percentage for categorical variables, mean \pm standard deviation for continuous variables with normal distribution and median (lower quartile, upper quartile) for skewed distributions. Chisquare test (or Fisher's exact test for expected sample size $<5$ ) was used for analysis of categorical variables, Student's $t$-test for continuous variables between groups, one-way analysis of variance for continuous variables with normal distribution for multiple groups and Kruskal-Wallis test for skewed distributions. Linear regression analysis was used to identify multicollinearity among potential predictors that were subsequently excluded from multivariate analysis. Logistic regression analysis was carried out to determine significant predictors associated with mortality of HIE newborns at discharge. The following independent variables used were identified based on the results of univariate analysis of survivors and non-survivors with p-values $<0.001$, and after excluding variables with multicollinearity: abruptio placentae, mode of delivery, gestational age, chest compression at birth, admission temperature, outborn status, severity of HIE, MAS, persistent pulmonary hypertension of the newborn (PPHN), sepsis, conventional ventilation and pneumothorax. A p-value $<0.05$ was considered statistically significant.

\section{RESULTS}

HIE was reported in a total of 919 newborns, 768 (83.6\%) of whom were inborn. There were 285,454 live births at the participating hospitals. The mean incidence of HIE was 2.59 per 1,000 live births/hospital (95\% confidence interval [CI] 2.03, 3.14) (Fig. 1). Table I shows the incidence of HIE according to ethnicity, mode of delivery, gestational age and birth weight. HIE was most common in foreigners (with Sabah natives having the highest incidence among Malaysians), newborns delivered by forceps, and term newborns with higher birth weight and lower gestational age. The incidence of HIE was lowest in newborns delivered by elective lower segment Caesarean section (LSCS). Of the 919 newborns with HIE, 307 (33.4\%), 423 (46.0\%) and $189(20.6 \%)$ had mild, moderate and severe HIE, respectively (Table II).

The mothers of the affected newborns had a mean age of 27.7 years (Table II). Anaemia and diabetes mellitus were the most common maternal illnesses. There was no significant difference in maternal age, ethnicity, anaemia, hypertension, eclampsia, chorioamnionitis, placenta previa, cord prolapse and use of intrapartum antibiotics among the mothers of newborns of different HIE grades. However, mothers of newborns with severe HIE had significantly higher gravid and parity status, and higher rates of abruptio placentae than those with moderate HIE.

Table III shows the neonatal characteristics of the newborns with HIE. About one-third of all newborns with HIE were born via LSCS and more than $95 \%$ of these births occurred in emergency situations. The median Apgar score was less than 6. More than $80 \%$ of them received oxygen therapy, bag-and-mask ventilation and/or endotracheal ventilation at birth. A significantly higher proportion of newborns with severe HIE were delivered by LSCS compared to those with moderate HIE $(p=0.024)$. Apgar scores 
Table I. Incidence of hypoxic-ischaemic encephalopathy (HIE) among newborns in the 2012 Malaysian National Neonatal Registry.

\begin{tabular}{|c|c|c|c|}
\hline \multirow[t]{2}{*}{ Variable } & \multicolumn{3}{|c|}{ No. } \\
\hline & $\begin{array}{l}\text { Total live births } \\
\text { (n = 285,454) }\end{array}$ & $\begin{array}{c}\text { Inborn } \\
\text { newborns with } \\
\text { HIE (n= 768) }\end{array}$ & $\begin{array}{l}\text { Incidence } \\
\text { of HIE* }\end{array}$ \\
\hline \multicolumn{4}{|l|}{ Ethnicity $^{+}$} \\
\hline Malay & 188,578 & 477 & 2.53 \\
\hline Chinese & 22,927 & 39 & 1.70 \\
\hline Indian & 14,294 & 33 & 2.31 \\
\hline Aboriginal & 2,388 & 1 & 0.42 \\
\hline Sabah native & 15,624 & 50 & 3.20 \\
\hline Sarawak native & 14,915 & 27 & 1.81 \\
\hline Foreigner & 22,646 & 133 & 5.87 \\
\hline Other Malaysian & 4,080 & 8 & 1.96 \\
\hline \multicolumn{4}{|l|}{ Mode of delivery } \\
\hline SVD & 201,620 & 316 & 1.57 \\
\hline Breech & 1,311 & 15 & 11.44 \\
\hline Forceps & 1,189 & 23 & 19.34 \\
\hline Vacuum extraction & 10,226 & 166 & 16.23 \\
\hline \multicolumn{4}{|l|}{ LSCS } \\
\hline Emergency & 17,438 & 240 & 13.76 \\
\hline Elective & 53,670 & 8 & 0.15 \\
\hline \multicolumn{4}{|l|}{$\begin{array}{l}\text { Gestational age }{ }^{\ddagger} \\
\text { (wk) }\end{array}$} \\
\hline 36 & 12,768 & 39 & 3.05 \\
\hline $37-40$ & 216,494 & 690 & 3.19 \\
\hline$>40$ & 39,245 & 39 & 0.99 \\
\hline \multicolumn{4}{|l|}{ Birth weight ${ }^{\S}(\mathrm{g})$} \\
\hline $1,501-2,000$ & 7,954 & $12^{\pi}$ & 1.51 \\
\hline $2,001-2,500$ & 32,314 & 82 & 2.54 \\
\hline$>2,500$ & 240,676 & 674 & 2.80 \\
\hline
\end{tabular}

*No. of inborn newborns with HIE per 1,000 live births. tEthnicity of 2 newborns not reported. $\$ 16,947$ live births not included, as they were of gestational age $<36$ weeks. ${ }^{\$} 4,510$ newborns were of birth weight $<1,501$ g. "One of these newborn weighed 1,408 g. LSCS: lower segment Caesarean section; SVD: spontaneous vertex delivery

at one minute and five minutes were significantly lower as the severity of HIE increased. Higher proportions of newborns with severe HIE received chest compressions when compared to newborns with moderate $(p<0.001)$ and mild HIE $(p<0.001)$. More newborns with severe $(p<0.001)$ and moderate HIE $(p<0.0001)$ needed endotracheal tube ventilation at birth when compared to those with mild HIE. More newborns with severe HIE $(p<0.001)$ received adrenaline at birth than those with mild and moderate HIE.

Seizures and MAS were common among all affected newborns. More than $90 \%$ of all newborns required respiratory support and the total mortality (15.7\%) was high (Table IV). When compared to newborns with mild and moderate HIE, those with severe HIE had significantly lower admission temperatures; significantly higher rates of seizures, PPHN, sepsis and respiratory support; significantly longer duration on all types of ventilation, including conventional ventilation; significantly higher mortality; and longer hospital stays among survivors $(p<0.01)$.
Table $\mathrm{V}$ shows a comparison of intrapartum, perinatal and neonatal factors between non-survivors and survivors of HIE. Univariate analysis showed that non-survivors had significantly higher proportions of abruptio placentae and LSCS; lower Apgar scores; lower admission temperatures; higher proportions of outborns, MAS, PPHN, respiratory support, pneumothorax, sepsis and severe $\mathrm{HIE}$; and received more resuscitation at birth with oxygen, chest compression and adrenaline.

After excluding variables with multicollinearity (i.e. Apgar scores at one and five minutes, adrenaline at birth and highfrequency ventilation), logistic regression analysis showed that the only significant predictors of mortality before discharge were: chest compression at birth (adjusted odds ratio [OR] 2.27, 95\% $\mathrm{Cl} 1.27,4.05 ; \mathrm{p}=0.003$ ), outborn (adjusted OR 2.65, 95\% Cl $1.36,5.13 ; \mathrm{p}=0.004$ ), MAS (adjusted OR $2.16,95 \% \mathrm{Cl} 1.05$, 4.47; $\mathrm{p}=0.038$ ), PPHN (adjusted OR 4.39, 95\% Cl 1.85, 10.43; $\mathrm{p}=0.001$ ), sepsis (adjusted $\mathrm{OR} 4.46,95 \% \mathrm{Cl} 1.38,14.40$; $\mathrm{p}=0.013$ ), pneumothorax (adjusted OR 4.77, 95\% Cl 1.76, $12.95 ; \mathrm{p}=0.002$ ) and severe HIE (adjusted OR 42.41, 95\% Cl $18.55,96.96 ; p<0.0001)$. The Nagelkerke $R^{2}$ value of the model was 0.582 .

During the study period, only seven of the NICUs were each equipped with one set of facilities for cooling therapy. Although these NICUs had a higher number of newborns with HIE (median 26.0, IQR 11.0-50.0) than centres without cooling facilities (median 15.5, IQR 13.0-22.3), this difference was not statistically significant $(p=0.26)$. Furthermore, although the mortality rates of these NICUs were lower (median 14.3\%, IQR 8.3\%-21.4\%) than those of NICUs without cooling facilities (median $20.0 \%$, IQR $11.0 \%-29.9 \%$ ), this difference was also not statistically significant $(p=0.24)$.

\section{DISCUSSION}

The MNNR was set up in 2004 with the aim of improving the standard of neonatal care in Malaysian NICUs. Participation in the registry was voluntary. During the early years of the MNNR, the inclusion criteria for newborns were: very low birth weight $(<1,500 \mathrm{~g})$ or preterm with gestational age $>32$ weeks; the presence of major congenital malformations; and requiring respiratory support. In 2012, all newborns diagnosed to have HIE were included in the database to aid in determining the extent of the morbidity and mortality of this condition in Malaysia. The findings in this study were representative of the majority of Malaysian NICUs in 2012, as 37 out of 40 NICUs in Malaysian public hospitals participated. Furthermore, the majority of the NICUs in Malaysian private hospitals had very small NICUs and were known to have transferred their seriously ill neonates to these public hospitals.

Although the incidence of HIE varied widely among these 37 Malaysian hospitals, the mean incidence of HIE per hospital (2.59 per 1,000 live births) was higher than the population-based incidence reported in the United Kingdom (1.94 per 1,000 live births), (1) Western Australia (0.97 per 1,000 live births), ${ }^{(2)}$ and Sweden (1.75 per 1,000 live births). ${ }^{(3)}$ However, when compared with the hospital-based or region-based incidence reported in 
Table II. Maternal characteristics of newborns with hypoxic-ischaemic encephalopathy (HIE) in the 2012 Malaysian National Neonatal Registry.

\begin{tabular}{|c|c|c|c|c|}
\hline \multirow[t]{2}{*}{ Variable } & \multicolumn{4}{|c|}{ No. (\%) } \\
\hline & Total $(n=919)$ & Mild HIE (n = 307) & Moderate HIE (n = 423) & Severe HIE $(n=189)$ \\
\hline Age* (yr) $^{*}$ & $27.7 \pm 5.8$ & $27.7 \pm 5.6$ & $27.7 \pm 5.8$ & $27.7 \pm 6.0$ \\
\hline \multicolumn{5}{|l|}{ Ethnicity } \\
\hline Malay & $575(62.6)$ & $193(62.9)$ & $277(65.5)$ & $105(55.6)$ \\
\hline Chinese & $47(5.1)$ & $14(4.6)$ & $21(5.0)$ & $12(6.3)$ \\
\hline Indian & $40(4.4)$ & $14(4.6)$ & $13(3.1)$ & $13(6.9)$ \\
\hline Aboriginal & $4(0.4)$ & 0 & $2(0.5)$ & $2(1.1)$ \\
\hline Sabah native & $60(6.5)$ & $27(8.8)$ & $18(4.3)$ & $15(7.9)$ \\
\hline Sarawak native & $35(3.8)$ & $8(2.6)$ & $18(4.3)$ & $9(4.8)$ \\
\hline Foreigner & $150(16.3)$ & $47(15.3)$ & $71(16.8)$ & $32(16.9)$ \\
\hline Other Malaysian & $8(0.9)$ & $4(1.3)$ & $3(0.7)$ & $1(0.5)$ \\
\hline Gravida $^{+}$ & $1(1,2)$ & $1(1,2)$ & $1(1,2)$ & $1(1,3)^{\ddagger}$ \\
\hline Diabetes mellitus & $130 / 884(14.7)$ & $56 / 300(18.7)$ & $46 / 409(11.2)^{\ddagger}$ & $28 / 175(16.0)$ \\
\hline Anaemia & $181 / 887(20.4)$ & $70 / 301$ (23.3) & $72 / 409$ (17.6) & $39 / 177(22.0)$ \\
\hline Hypertension & 74/889 (8.3) & $27 / 302(8.9)$ & $30 / 411(7.3)$ & $17 / 176(9.7)$ \\
\hline Eclampsia & $18 / 897(2.0)$ & 9/303 (3.0) & $7 / 415$ (1.7) & $2 / 179(1.1)$ \\
\hline Chorioamnionitis & $11 / 895(1.2)$ & $3 / 303$ (1.0) & $5 / 414(1.2)$ & $3 / 178(1.7)$ \\
\hline Abruptio placentae & 24/918 (2.6) & $8(2.6)$ & $5(1.2)$ & $11 / 188(5.9)^{\|}$ \\
\hline Placenta previa & $3 / 917$ (0.3) & $3 / 306$ (1.0) & 0 & $0 / 188$ \\
\hline Cord prolapse & $27 / 918(2.9)$ & $11(3.6)$ & $9(2.1)$ & $7 / 188(3.7)$ \\
\hline Intrapartum antibiotics & $80 / 901$ (8.9) & $25 / 302(8.3)$ & $40 / 414(9.7)$ & $15 / 185(8.1)$ \\
\hline
\end{tabular}

Value of $\mathrm{n}$ is provided for variables with missing data. *Data presented as mean \pm standard deviation. + Data presented as median (lower quartile, upper quartile).



Table III. Characteristics of newborns with hypoxic-ischaemic encephalopathy (HIE) in the 2012 Malaysian National Neonatal Registry.

\begin{tabular}{|c|c|c|c|c|c|}
\hline \multirow[t]{2}{*}{ Variable } & \multicolumn{4}{|c|}{ No. (\%) } & \multirow[t]{2}{*}{ p-value* } \\
\hline & $\begin{array}{c}\text { Total } \\
(\mathrm{n}=919)\end{array}$ & $\begin{array}{l}\text { Mild HIE } \\
(n=307)\end{array}$ & $\begin{array}{l}\text { Moderate HIE } \\
(n=423)\end{array}$ & $\begin{array}{c}\text { Severe HIE } \\
(n=189)\end{array}$ & \\
\hline Gestational age ${ }^{+}$(wk) & $38.8 \pm 1.3$ & $38.8 \pm 1.3$ & $38.9 \pm 1.2$ & $38.7 \pm 1.3$ & 0.086 \\
\hline Growth status & & & & & 0.596 \\
\hline AGA & $751(81.7)$ & $259(84.4)$ & $338(79.9)$ & $154(81.5)$ & \\
\hline LGA & $34(3.7)$ & $11(3.6)$ & $17(4.0)$ & $6(3.2)$ & \\
\hline SGA & $134(14.6)$ & $37(12.1)$ & $68(16.1)$ & $29(15.3)$ & \\
\hline Male & $592(64.4)$ & $198(64.5)$ & $289(68.3)$ & $105(55.6)$ & $0.010^{\ddagger}$ \\
\hline Singleton & $904(98.4)$ & $300(97.7)$ & $418(98.8)$ & $186(98.4)$ & 0.512 \\
\hline Mode of delivery & & & & & $<0.0001^{*}$ \\
\hline Vaginal & $430(46.8)$ & $118(38.4)$ & $234(55.3)$ & $78(41.3)$ & \\
\hline All LSCS & $287(31.2)$ & 104 (33.9) & $96(22.7)$ & $87(46.0)$ & \\
\hline Emergency & $275(95.8)$ & 97 (93.3) & $94(97.9)$ & $84(96.6)$ & 0.239 \\
\hline \multicolumn{6}{|l|}{ Apgar score $^{+}$} \\
\hline At $1 \mathrm{~min}$ & $3.5 \pm 2.2(n=895)$ & $4.1 \pm 2.1(n=300)$ & $3.5 \pm 1.9(n=414)$ & $2.4 \pm 2.3(n=181)$ & $<0.0001^{*}$ \\
\hline At $5 \mathrm{~min}$ & $5.4 \pm 2.4(n=856)$ & $6.3 \pm 2.2(n=292)$ & $5.5 \pm 2.0(n=396)$ & $3.6 \pm 2.8(n=168)$ & $<0.0001^{*}$ \\
\hline \multicolumn{6}{|l|}{ Resuscitation at birth } \\
\hline Oxygen & $852 / 890(95.7)$ & $282 / 300(94.0)$ & $394 / 404(97.5)$ & $176 / 186(94.6)$ & 0.051 \\
\hline Bag-and-mask ventilation & $799 / 890(89.8)$ & $260 / 300(86.7)$ & $369 / 404$ (91.3) & $170 / 186(91.4)$ & 0.092 \\
\hline Chest compression & $171 / 888$ (19.3) & $30 / 300(10.0)$ & $59 / 404(14.6)$ & $82 / 184(44.6)$ & $<0.0001^{*}$ \\
\hline ETT ventilation & $748 / 890(84.0)$ & $224 / 300(74.7)$ & $354 / 404(87.6)$ & $170 / 186(91.4)$ & $<0.0001^{*}$ \\
\hline Adrenaline & $105 / 887$ (11.8) & $13 / 300(4.3)$ & $23 / 403(5.7)$ & $69 / 184(37.5)$ & $<0.0001^{*}$ \\
\hline Outborn & $151(16.4)$ & $35(11.4)$ & $78(18.4)$ & $38(20.1)$ & $0.013^{\ddagger}$ \\
\hline
\end{tabular}

Value of $\mathrm{n}$ is provided for variables with missing data. ${ }^{*}$ Comparison among newborns with mild, moderate and severe HIE. $\mathrm{tData}$ presented as mean \pm standard deviation. $¥ p$-value is statistically significant. AGA: appropriate for gestational age; ETT: endotracheal tube; LGA: large for gestational age; LSCS: lower segment Caesarean section; SGA: small for gestational age 
Table IV. Clinical problems and outcomes of newborns with hypoxic-ischaemic encephalopathy (HIE) in the 2012 Malaysian National Neonatal Registry.

\begin{tabular}{|c|c|c|c|c|c|}
\hline \multirow[t]{2}{*}{ Variable } & \multicolumn{4}{|c|}{ No. (\%) } & \multirow[t]{2}{*}{ p-value* } \\
\hline & $\begin{array}{c}\text { Total } \\
(n=919)\end{array}$ & $\begin{array}{l}\text { Mild HIE } \\
(n=307)\end{array}$ & $\begin{array}{c}\text { Moderate HIE } \\
\quad(n=423)\end{array}$ & $\begin{array}{c}\text { Severe HIE } \\
(n=189)\end{array}$ & \\
\hline Seizures & $487(53.0)$ & 52 (16.9) & 317 (74.9) & $118(62.4)$ & $<0.0001^{\S}$ \\
\hline MAS & $167(18.2)$ & 52 (16.9) & 84 (19.9) & $31(16.4)$ & 0.467 \\
\hline PPHN & $71 / 914(7.8)$ & $11 / 305(3.6)$ & $39 / 422(9.2)$ & $21 / 187(11.2)$ & $0.003^{\S}$ \\
\hline Sepsis & $29(3.2)$ & $5(1.6)$ & $12(2.8)$ & $12(6.3)$ & $0.012^{\S}$ \\
\hline Early onset & $13(44.8)$ & $2(40.0)$ & $8(66.7)$ & $3(25.0)$ & 0.118 \\
\hline Late onset & $16(55.2)$ & $3(60.0)$ & $4(33.3)$ & $9(75.0)$ & \\
\hline Respiratory support* & $858(93.4)$ & $262(85.3)$ & $410(96.9)$ & $186(98.4)$ & $<0.0001^{\S}$ \\
\hline CPAP & $245(28.6)$ & $90(34.4)$ & $115(28.0)$ & $40(21.5)$ & $0.012^{\S}$ \\
\hline Conventional ventilation & $777(90.6)$ & $212(80.9)$ & $387(94.4)$ & $178(95.7)$ & $<0.0001^{\S}$ \\
\hline iNO therapy & $20(2.3)$ & $5(1.9)$ & $9(2.2)$ & $6(3.2)$ & 0.640 \\
\hline \multicolumn{6}{|l|}{ Duration on ventilation ${ }^{+}$(day) } \\
\hline All types & $\begin{array}{c}2(1,5) \\
(n=897)\end{array}$ & $\begin{array}{c}1(0,2) \\
(n=291)\end{array}$ & $\begin{array}{c}3(2,5) \\
(n=419)\end{array}$ & $\begin{array}{c}4(1,7) \\
(n=187)\end{array}$ & $<0.0001^{\S}$ \\
\hline Conventional & $3(1,5)$ & $1(1,3)$ & $3(2,5)$ & $4(2,7)$ & $<0.0001^{\S}$ \\
\hline Pneumothorax & $45(4.9)$ & $13(4.2)$ & $22(5.2)$ & $10(5.3)$ & 0.804 \\
\hline Died & $144(15.7)$ & $9(2.9)$ & $22(5.2)$ & $113(59.8)$ & $<0.0001^{\S}$ \\
\hline Length of hospital stay+ (day) & $7(4,12)$ & $5(4,8)$ & $8(6,13)$ & $7(2,19)$ & $<0.0001^{\S}$ \\
\hline Survivor & $\begin{array}{l}8(5,12) \\
(n=775)\end{array}$ & $\begin{array}{c}5(4,8) \\
(n=298)\end{array}$ & $\begin{array}{l}9(6,13) \\
(n=401)\end{array}$ & $\begin{array}{c}20(10,29) \\
(n=76)\end{array}$ & $<0.0001^{\S}$ \\
\hline
\end{tabular}

Value of $\mathrm{n}$ is provided for variables with missing data. *Comparison among newborns with mild, moderate and severe HIE. †Data presented as median (lower quartile, upper quartile). ¥More than one type of respiratory support was used for some newborns. §p-value is statistically significant. CPAP: continuous positive airway pressure; HFV: high-frequency ventilation; iNO: inhaled nitric oxide; MAS: meconium aspiration syndrome; PPHN: persistent pulmonary hypertension of the newborn

the 1980s and 1990s in countries such as the United Kingdom (4.6-6.0 per 1,000 live births in the 1980s), ${ }^{(8,9)}$ Sweden (1.8 per 1,000 live births in 1985-1991), ${ }^{(4)}$ the United States (4.5 per 1,000 live births in the 1990s) ${ }^{(10)}$ and Saudi Arabia (5.5 per 1,000 live births in the 1990s), ${ }^{(11)}$ our incidence was lower.

A system for referring high-risk pregnancies to major government hospitals has been in place in Malaysia for more than two decades. Since September 1996, neonatal resuscitation training programmes based on the American Heart Association and American Academy of Paediatrics' Neonatal Resuscitation Program (NRP) have been systematically implemented in all government hospitals in Malaysia. All paediatric and obstetric medical and nursing staff in all Malaysian government hospitals are trained in the NRP. ${ }^{(12,13)}$ However, recertification training for the NRP, which should be conducted every two years, has not been stringently implemented.

The difference in HIE incidence among the 37 hospitals in the MNNR could be due to many factors, such as differences in patient profiles, and antenatal, intrapartum and resuscitation care. In the case-control studies reported previously by other investigators, ${ }^{(3,4,14)}$ maternal diabetes mellitus, anaemia and hypertension were reported to be significant risk factors associated with HIE. In the present study, we were unable to identify risk factors associated with HIE in these Malaysian hospitals, as the 2012 MNNR database included only term newborns diagnosed to have HIE and those requiring respiratory support. All term newborns without HIE born in these participating hospitals were not included in the database. Nevertheless, the high incidence of HIE among newborns with instrumental deliveries and emergency LSCS (Table I), and the high proportions of HIE newborns with low Apgar scores requiring extensive resuscitation at birth (Table III) in this study suggest that intrapartum factors could be significant risk factors associated with HIE in Malaysian hospitals; this is similar to observations by investigators elsewhere. ${ }^{(15,16)}$ Further studies are urgently needed to identify these risk factors and determine whether earlier recognition of obstetric problems and increasing the frequency of intrapartum monitoring could help to improve the incidence of HIE. Studies are also needed to determine the competence of NRP-certified staff in performing newborn resuscitation in labour rooms in Malaysia, as training does not imply competence and systematic retraining may be needed for NRP-certified staff. ${ }^{(17)}$

In 2012, only six NICUs in the MNNR were able to perform amplitude integrated electroencephalography (aEEG) for CFM. Few NICUs $(n=4)$ had ready access to electroencephalography (EEG) in their hospitals. In 2012, the severity of HIE in the MNNR was graded based solely on the level of consciousness and muscle tone of newborns on admission, instead of the presence or absence of seizures and EEG changes as required in the original criteria by Sarnat and Sarnat. ${ }^{(18)}$ Based on our modified method of grading $\mathrm{HIE}, 16.9 \%$ of newborns categorised under mild HIE in the present study had seizures and would be classified as having 
Table V. Comparison of non-survivors and survivors of hypoxic-ischaemic encephalopathy (HIE) in the 2012 Malaysian National Neonatal Registry ( $n=919)$.

\begin{tabular}{|c|c|c|c|}
\hline \multirow[t]{2}{*}{ Variable } & \multicolumn{2}{|c|}{ No. (\%) } & \multirow[t]{2}{*}{ p-value } \\
\hline & Non-survivors $(n=144)$ & Survivors $(n=775)$ & \\
\hline \multicolumn{4}{|l|}{ Maternal } \\
\hline Age* $^{*}(y r)$ & $28(24,33)$ & $27(24,31)$ & 0.941 \\
\hline Gravid* & $2(1,3)$ & $1(1,2)$ & 0.051 \\
\hline Parity* & $0(0,2)$ & $0(0,1)$ & 0.014 \\
\hline Malay ethnicity & $85(59.0)$ & $490(63.2)$ & 0.189 \\
\hline Diabetes mellitus & $20 / 127(15.7)$ & $110 / 757(14.5)$ & 0.720 \\
\hline Hypertension & $15 / 128(11.7)$ & $59 / 761(7.8)$ & 0.095 \\
\hline Eclampsia & $2 / 131(1.5)$ & $16 / 766(2.1)$ & 1.00 \\
\hline Chorioamnionitis & $2 / 130(1.5)$ & $9 / 765(1.2)$ & 0.667 \\
\hline Anaemia & 25/129 (19.4) & $156 / 758(20.6)$ & 0.754 \\
\hline Abruptio placentae & $10 / 143(7.0)$ & $14(1.8)$ & $0.002^{\ddagger}$ \\
\hline Placenta previa & 0 & $3 / 774(0.4)$ & 1.00 \\
\hline Cord prolapse & $4 / 143(2.8)$ & $23(3.0)$ & 1.000 \\
\hline Intrapartum antibiotics & $9 / 139(6.5)$ & $71 / 762(9.3)$ & 0.279 \\
\hline LSCS delivery & $71(49.3)$ & $216(27.9)$ & $<0.0001^{*}$ \\
\hline Birth weight $^{+}(\mathrm{g})$ & $3,030 \pm 481$ & $3,072 \pm 486$ & 0.346 \\
\hline Gestational age (wk) & $38.6 \pm 1.4$ & $38.8 \pm 1.3$ & 0.044 \\
\hline SGA & $25(17.4)$ & $109(14.1)$ & 0.587 \\
\hline \multicolumn{4}{|l|}{ Apgar score* } \\
\hline At $1 \mathrm{~min}$ & $2(0,4)(n=133)$ & $4(2,5) \quad(n=762)$ & $<0.001^{*}$ \\
\hline At $5 \mathrm{~min}$ & $4(1,6)(n=127)$ & $6(4,7)(n=729)$ & $<0.001^{*}$ \\
\hline \multicolumn{4}{|l|}{ Resuscitation at birth } \\
\hline Oxygen at birth & $128 / 139(92.1)$ & $724 / 751(96.4)$ & $0.036^{*}$ \\
\hline Bag-and-mask ventilation & $122 / 139(87.8)$ & $677 / 751(90.1)$ & 0.445 \\
\hline Chest compression & $66 / 138(47.8)$ & $105 / 750(14.0)$ & $<0.001^{*}$ \\
\hline ETT ventilation & $122 / 139(87.8)$ & $626 / 751(83.4)$ & 0.192 \\
\hline Adrenaline & $55 / 137(40.1)$ & $50 / 750(6.7)$ & $<0.001^{*}$ \\
\hline Outborn & $38(26.5)$ & $113(14.6)$ & $<0.001^{*}$ \\
\hline Admission temperature ${ }^{*}\left({ }^{\circ} \mathrm{C}\right)$ & $36.0(34.9,36.5)$ & $36.3(35.7,36.6)$ & $<0.0001^{*}$ \\
\hline Seizures & $73(50.7)$ & $414(53.4)$ & 0.547 \\
\hline MAS & $40(27.8)$ & $127(16.4)$ & $0.001^{\ddagger}$ \\
\hline PPHN & $31(21.5)$ & $40 / 770(5.2)$ & $<0.0001^{*}$ \\
\hline Respiratory support & $141(97.9)$ & $717(92.5)$ & $0.017^{\ddagger}$ \\
\hline CPAP & $8 / 141(5.7)$ & 237/717 (33.1) & $<0.0001^{*}$ \\
\hline Conventional ventilation & $134(95.0)$ & $643(89.7)$ & $0.047^{*}$ \\
\hline High-frequency ventilation & $35(24.8)$ & $24(3.3)$ & $<0.0001^{*}$ \\
\hline iNO therapy & $9 / 141(6.4)$ & $11 / 717(1.5)$ & $0.002^{\ddagger}$ \\
\hline Pneumothorax & $17(11.8)$ & $28(3.6)$ & $<0.0001^{*}$ \\
\hline Sepsis & $12(8.3)$ & $17(2.2)$ & $<0.0001^{*}$ \\
\hline Late onset & $9(75.0)$ & $7(41.2)$ & 0.076 \\
\hline HIE stage & & & $<0.0001^{\ddagger}$ \\
\hline Mild & $9(6.3)$ & $298(38.5)$ & \\
\hline Moderate & $22(15.3)$ & $401(51.7)$ & \\
\hline Severe & $113(78.5)$ & $76(9.8)$ & \\
\hline
\end{tabular}

*Data presented as median (lower quartile, upper quartile). †Data presented as mean \pm standard deviation. ₹p-value is statistically significant. CPAP: continuous positive airway pressure; ETT: endotracheal tube; iNO: inhaled nitric oxide; LSCS: lower segment Caesarean section; MAS: meconium aspiration syndrome; PPHN: persistent hypertension of newborn; SGA: small for gestational age

at least moderate HIE according to Sarnat and Sarnat's criteria. Hence, our method could have resulted in underdiagnosis of the severity of HIE. These findings provide evidence of the need to adopt the full criteria from Sarnat and Sarnat to categorise the severity of HIE. In addition, equipping all Malaysian NICUs with aEEG capabilities would help staff to detect clinically subtle seizures and confirm obvious ones for staging, management and prediction of outcome. 
Our data revealed that a majority of HIE newborns were seriously ill after admission, as more than $90 \%$ of them needed ventilator support. Furthermore, the more severe the HIE, the higher the morbidity and mortality among these HIE newborns. A number of significant predictors were identified. Univariate analysis showed that besides Apgar scores and adrenaline at birth (similar to a report by Toh in a previous study with a small sample size), ${ }^{(19)}$ chest compression, PPHN and MAS were significant predictors. However, in the present study, Apgar scores and adrenaline were found to be highly correlated with chest compression, PPHN and MAS in tests of multicollinearity. These two factors (Apgar scores and adrenaline at birth) were therefore not included in the logistic regression analysis. After controlling for various potential confounders, logistic regression analysis showed that newborns in our NICUs who had severe HIE, chest compression at birth, MAS, PPHN, sepsis and pneumothorax, and were outborn were more likely to die before discharge, confirming Toh's findings to some extent. ${ }^{(19)}$

In 2012, only seven NICUs in the MNNR were equipped with a set of facilities for cooling therapy and only one affected newborn could receive cooling therapy at a time in each centre. Numerous studies have shown that cooling therapy improves the early and long-term outcome of newborns with HIE. ${ }^{(1,20-23)}$ Given the large number of newborns in the MNNR who were graded with moderate and severe HIE, facilities for cooling therapy should be provided to all Malaysian NICUs and in an adequate number in order to reduce the morbidity and mortality associated with this condition.

Apart from our possible misclassification of HIE severity, this study had a few other limitations. Risk factors associated with HIE in the NICUs could not be identified because the perinatal and neonatal data of all term newborns with and without HIE in these hospitals was not included in the MNNR database. The criteria for newborns to receive cooling therapy in centres with cooling facilities were also not identified in the database; hence, we could not determine whether cooling made a difference in their outcome compared with newborns in the same centre who did not receive cooling therapy.

In conclusion, the incidence of HIE in Malaysian NICUs was similar to that reported in developed countries in the 1990s. The morbidity and mortality of HIE newborns were high in Malaysian NICUs. There is an urgent need to identify the risk factors associated with this problem for effective preventive steps to be taken, and to equip all Malaysian NICUs with CFM and facilities for cooling therapy, so as to improve the diagnosis and management of this group of high-risk newborns.

\section{ACKNOWLEDGEMENTS}

We would like to thank the Director General of the Ministry of Health, Malaysia, for giving us permission to publish this paper and the site coordinators of the participating hospitals: Zuraidah Abdul Latif (Hospital Ampang), Zainah Shaik Hedra (Hospital Batu Pahat), Anand Mohana Lal (Hospital Bintulu), Baizura Jamaluddin (Hospital Kajang), Ubhaya Kumar (Hospital Keningau), SiewHong Neoh (Hospital Kuala Lumpur), Anusha A/P Palakrishanan
(Hospital Kuala Pilah), Mohd Shafie Hamid (Hospital Kulim), PoyLee Leow (Hospital Melaka), Siao-Hean Teh (Miri Hospital), JenJen Leong (Pulau Pinang Hospital), Nor Diana Yahya (Putrajaya Hospital), Noor Khatijah bt Nurani (Hospital Raja Permaisuri Bainun, Ipoh), Hasmawati Hassan (Hospital Raja Perempuan Zainab II, Kota Bharu), Maneet Kaur (Sabah Women and Children Hospital), Lee-Gaik Chan (Sarawak General Hospital), Angeline Yeoh (Seberang Jaya Hospital), Rohaizah Borhan (Serdang Hospital), Seok-Chiong Chee (Selayang Hospital), Sow-Keng Chan (Seri Manjung Hospital), Matthew Hon-Loon Chong (Hospital Sandakan), Intan Nur Chahaya Abdul Shukor (Hospital Segamat), Audrey Chae-Hee Chieng (Sibu Hospital), Ying-Beih Tan (Hospital Sultan Abdul Halim, Sungai Petani), Keng-Hwang Teh (Hospital Sultanah Bahiyah, Alor Setar), Neesa Amran (Hospital Sultan Haji Ahmad Shah, Temerloh), Unnikrishnan Gopinathan (Sultanah Aminah Hospital, Johor Bahru), Pui-Ying Tam (Sultanah Fatimah Specialist Hospital, Muar), Sharifah Huda Engku Alwi (Sultanah Nur Zahirah Hospital, Kuala Terengganu), Kwee-Ching See (Sungai Buloh Hospital), Saiful Rijal (Taiping Hospital), Kogilavani Gunasagaran (Teluk Intan Hospital), Choy-Nyok Chin (Tengku Ampuan Afzan Hospital, Kuantan), Yogeswary Sithamparanathan (Tengku Ampuan Rahimah Hospital, Klang), Hazimah Mohd Yusoff (Tuanku Fauziah Hospital, Kangar), Umathevi Paramasivam (Tuanku Ja'afar Hospital, Seremban), Noraida Ramli (Universiti Sains Malaysia Hospital). This study was funded by the Ministry of Health, Malaysia, and Perinatal Society of Malaysia.

\section{REFERENCES}

1. Smith J, Wells L, Dodd K. The continuing fall in incidence of hypoxicischaemic encephalopathy in term infants. BJOG 2000; 107:461-6.

2. Badawi N, Kurinczuk JJ, Keogh JM, et al. Intrapartum risk factors for newborn encephalopathy: the Western Australia case-control study. BMJ 1998; 317:1554-8.

3. Thornberg E, Thiringer K, Odeback A, Milsom I. Birth asphyxia: incidence, clinical course and outcome in a Swedish population. Acta Paediatr 1995; 84:927-32.

4. Graham EM, Ruis KA, Hartman AL, Northington FJ, Fox HE. A systematic review of the role of intrapartum hypoxia-ischemia in the causation of neonatal encephalopathy. Am J Obstet Gynecol 2008; 199:587-95.

5. Jacobs SE, Berg M, Hunt R, et al. Cooling for newborns with hypoxic ischaemic encephalopathy. Cochrane Database Syst Rev 2013; 1:CD003311.

6. Eunice Kennedy Shriver National Institute of Child Health and Human Development. Report of the Workshop on Acute Perinatal Asphyxia in Term Infants [online]. Available at: https://www.nichd.nih.gov/publications/pubs/ acute/Pages/acute.aspx\#Executive\%20Summary. Accessed October 1, 2014.

7. Kitchen WH, Robinson HP, Dickenson AJ. Revised intrauterine growth curves for an Australian hospital population. Aust Paediatr J 1983; 19:157-61.

8. Hull J, Dodd KL. Falling incidence of hypoxic-ischaemic encephalopathy in term infants. Br J Obstet Gynaecol 1992; 99:386-91.

9. Levene ML, Kornberg J, Williams TH. The incidence and severity of postasphyxial encephalopathy in full-term infants. Early Hum Dev 1985; 11:21-6.

10. Wu YW, Backstrand KH, Zhao S, Fullerton HJ, Johnston SC. Declining diagnosis of birth asphyxia in California: 1991-2000. Pediatrics 2004; 114:1584-90

11. Itoo BA, Al-Hawsawi ZM, Khan AH. Hypoxic ischemic encephalopathy. Incidence and risk factors in North Western Saudi Arabia. Saudi Med J 2003; 24:147-53.

12. Boo NY, Pong KM. Neonatal resuscitation training program in Malaysia: results of first 2 years. J Paediatr Child Health 2001; 37:118-24.

13. Boo NY. Neonatal resuscitation programme in Malaysia: an eight-year experience. Singapore Med J 2009; 50:152-9.

14. Ellis M, Manandhar N, Manandhar DS, Costello AM. Risk factors for 
neonatal encephalopathy in Kathmandu, Nepal, a developing country: unmatched case-control study. BMJ 2000; 320:1229-36.

15. Lee AC, Kozuki N, Blencowe $\mathrm{H}$, et al. Intrapartum-related neonata encephalopathy incidence and impairment at regional and global levels for 2010 with trends from 1990. Pediatr Res 2013; 74: Suppl 1:50-72.

16. Executive summary: Neonatal encephalopathy and neurologic outcome second edition. Report of the American College of Obstetricians and Gynecologists' Task Force on Neonatal Encephalopahty. Obstet Gynecol 2014; 123:896-901.

17. Cusack J, Fawke J. Neonatal resuscitation: are your trainees performing as you think they are? A retrospective review of a structured resuscitation assessment for neonatal medical trainees over an 8-year period. Arch Dis Child Fetal Neonatal Ed 2012; 97:F246-8.

18. Sarnat HB, Sarnat MS. Neonatal encephalopathy following fetal distress. A clinical and electroencephalographic study. Arch Neurol 1976; 33:696-705

19. Toh VC. Early predictors of adverse outcome in term infants with post- asphyxial hypoxic ischaemic encephalopathy. Acta Pædiatr 2000; 89:343-7. 20. Tagin MA, Woolcotte CG, Vincer MJ, Whyte RK, Stinson DA. Hypothermia for neonatal hypoxic ischemic encephalopathy: an updated systematic review and meta-analysis. Arch Pediatr Adolesc Med 2012; 166:558-66.

21. Gardiner J, Wagh D, McMichael J, Hakeem M, Rao S. Outcomes of hypoxic ischaemic encephalopathy treated with therapeutic hypothermia using cool gel packs - experience from Western Australia. Eur J Paediatr Neurol 2014; 18:391-8.

22. Azzopardi D, Strohm B, Marlow N, et al; TOBY Study group. Effects of hypothermia for perinatal asphyxia on childhood outcomes. N Engl J Med 2014; 371:140-9

23. See KC, Jamal SJ, Chiam ML. Short term outcome of therapeutic hypothermia in term infants with moderate to severe hypoxic ischaemic encephalopathy; the Sungai Buloh experience. Med J Malaysia 2012; 67:265-8. 